\title{
Serum level of Matrix metalloproteinase-9 in patients with systemic lupus erythematosus.
}

\author{
Ghada A. Abd El-Aziz*, Hanan M.A. Darwish*, Amal A. Morsy **, and \\ Sabila Gomma Mousa ***
}

Departments of Dermatology *, Clinical pathology**, and General Medicine ***, Faculty of Medicine for girls Al-Azhar university

\begin{abstract}
Background: Matrix metalloproteinase-9 (MMP-9) was involved in inflammation and immune system dysfunctions. Beside immunologic abnormalities, systemic lupus erythematosus (SLE) also presents chronic inflammatory components. Therefore, a role of MMP-9 in SLE pathology might be supposed.

Objective: To investigate the level of matrix metalloproteinase- 9 in systemic lupus erythematosus patients and to determine its value in monitoring disease activity.

Patients and methods: Twenty five SLE female patients were included in this study. Ten healthy females where selected as controls. The activity of SLE was evaluated according to SLAM scoring. Using quantitative ELISA Kit provided from R \& D system INC. USA, to quantitate the total levels of MMP-9. These levels were then compared and correlated with the ANA, anti-ds-DNA, lupus nephritis, Raynaud phenomenon, malar rash, photosensitivity, alopecia, and mucosal ulcers.

Results: serum of MMP-9 were found to be significantly higher $(\mathrm{P}<0.01)$, in SLE patients compared to the control group. Serum MMP-9 show statistical significant correlation with antids DNA, Lupus nephritis, Raynaud phenomenon, malar rash and photosensitivity and it did notshow any statistical significant correlation with ANA, alopecia and mucosal ulcers

Conclusion: The data suggest that MMP-9 could be involved in the pathogenesis of SLE, and serum MMP-9 can be used as marker to monitor disease activity, renal damage, disease progression and amelioration in SLE.
\end{abstract}

\section{Introduction}

Systemic lupus erythematosus (SLE) is a systemic autoimmune disease that exhibits various clinical manifestations, including immune complex depositions in the kidneys and other organs (Hahn, 1993).

The cause of the disease has not yet been defined yet. However, it involves the production of a broad spectrum of autoantibodies against nuclear, cytoplasmic and cell-surface antigens, and different impairments of B-and T-cell functions (winchester,1996). Proinflammatory cytokines, especially TNF- $\alpha$ and IL-1, were shown to play an important role in the pathogenesis of SLE through direct induction of matrix metalloproteinases (MMPs). Thus MMPs may play a role in the pathogenesis of SLE (Zhang et al., 1998).

Matrix metalloproteinases (MMPs) are a family of highly homologous $\mathrm{Zn}^{2++}$ dependent enzymes , capable of degrading the extracellular matrix (ECM) and bone marrow. They are present in healthy individuals and have been shown to play an important role in physiological processes such as wound healing, bone resorption and pregnancy. (Brehmer et al. 2003).

The potential importance of the many activities of MMPs in inflammatory responses has been suggested by the inhibitory effects of MMPs in several autoimmune diseases. Specific inhibitions 
of MMPs in vivo suppresses oedema, pathologic tissue proliferation, and damage to specialized tissue structures in several inflammatory and autoimmune diseases (Wallace et al., 1999).

Matrix metalloproteinase-9 (MMP-9) plays an important role in the degradation of type IV collagen, denaturation of collagens types V, VII, X, XII collagens, vitronectin agreecan, galectin-3 and elastin (Zhang et al, 1998). Faber-El-Mann et al. 2002B, and Matache et al., 2003 in two different studies reported that MMP-9 level was found to be elevated in the serum of SLE patients compared with helathy controls. High MMP-9 activity was found to correlate with the presence of discoid rash, Raynauds phenomenon, pneumonitis, mucosal ulcers and the presence of antiphospholipid antibodies (APLA).

The aim of this work is to measure the levels of (MMP-9) in sera of systemic lupus erythematosus patients and to determine its value in monitoring disease activity.

\section{Patients and methods}

A group of 25 female patients suffering from systemic lupus erythematosus (SLE) participated in this study. Their ages ranged from 12 to 35 years (With a mean age of $24.28 \pm 6.53$ ).

Ten age matched normal female controls with no family or personal history of SLE were included. Their ages ranged from 15 to 34 years. (with a mean age of $22.1 \pm 5.95$ ). All cases for this study were collected from the out patient clinics of dermatology and medicine in El-Zahraa university hospital. The patients were subjected to complete clinical evaluation thorough history taking and clinical examination which was performed according to the American Rheumatism Association (ARA) criteria. The activity of SLE was evaluated according to the systemic lupus activity measure (SLAM) score.

\section{Blood sampling}

Seven milliliters of venous blood were collected and divided into two tube. Three milliliters were collected in heparinized tube. The plasma was separated after centrifugation and stored at $-20{ }^{\circ} \mathrm{C}$ for determination of MMP-9.

Four milliliters blood were collected in plain tube and left for $20 \mathrm{~min}$. at $37^{\circ} \mathrm{C}$. Serum was separated after centrifugation and stored at $-20{ }^{\circ} \mathrm{C}$ for ANA and double stranded DNA estimation.

\section{The patients were subjected to:}

- Serum level of ANA and double stranded DNA were measured by (ELISA). Commercially available enzyme linked immunosorbent assay method by using their specific kits [B indazyme $^{\text {th }}$ ANA, double stranded DNA screen IVD] .

- Assessment of serum MMP-9 level by employing aquantitative sandwich ELISA technique using Quantikine ELISA Kit provided from $\mathrm{R} \& \mathrm{D}$ systems, inc., USA).

\section{Statistical analysis was done.}

Data was analyzed by Microsoft Office XP (excel).

Parametric data was expressed as mean $\pm \mathrm{SD}$, and non parametric data was expressed as number and percentage of the total.

Comparing the mean \pm SD of 2 groups was done using the student's test

Determining the extent that a single observed series of proportions differs from a theoretical or expected distribution was done using the Chi square test

$\mathrm{P}$ value $>0.05$ is considered nonsignificant

$\mathrm{P}$ value $<0.01$ is considered highly significant

\section{Results}

This study encompassed 25 patients with an age span of 12-35 years and 10 controls with an age span of 15-34 years. The duration of the disease ranged from $0.33-10$ years.

Table 1 and figure 1 represents the results of serum level of metalloproteinase 9 in SLE patients and controls. We obtained a mean serum MMP-9 level of 660.96 $\pm 305.21 \mathrm{ng} / \mathrm{ml}$ for SLE patients and 
$170.70 \pm 20.96 \mathrm{ng} / \mathrm{ml}$ for control group $(\mathrm{P}<0.01)$.

On comparing the serum level of MMP-9 in patients with positive Anti ds DNA and those with negative results, there was a highly statistically significant difference $(\mathrm{P}<0.01)$ and on comparing the serum level of MMP-9 in patients with positive ANA, and those with negative results, there was no significant difference (Table 2).

On comparing the serum level of MMP-9 in patients with positive renal affection and those with negative results, there was a highly significant difference $(\mathrm{P}<0.01)$ ( table 3$)$.
By comparing the serum level of MMP-9 in patients with positive Raymond's phenomenon and those with negative results, there was a highly significant difference $(\mathrm{P}<0.01)$ ( table 4 ). By comparing the serum level of MMP-9 in patients with presence of malar rash and photosensitivity and those with negative results, there was a highly significant difference $(\mathrm{P}<0.01)$ (Table 5).

Finally, on comparing serum level of MMP-9 in patients with presence of alopecia and mucosal ulcers and those with negative results, there was no statistically significant difference $(\mathrm{P}<0.01)$ ( Table 6$)$.

Table 1: Relationship between MMP-9 level in SLE patients and controls

\begin{tabular}{|l|l|l|l|}
\hline & $\begin{array}{l}\text { Mean } \\
\text { ng/ml }\end{array}$ & $\begin{array}{l}\text { SD } \\
\text { ng/ml }\end{array}$ & P Value \\
\hline Patients & 660.96 & 305.21 & $0.0000 *$ \\
\hline Control & 170.70 & 20.96 & \\
\hline
\end{tabular}

$\mathrm{SD}=$ Standard deviation

$P$ vlaue $<0.01$ significant

Table 2 : Relationship between MMP-9 level and anti ds DNA and ANA in SLE patients

\begin{tabular}{|l|l|l|l|l|l|}
\hline & & MMP-9 & & & \\
\hline & & Positive & Negative & Total & P Value \\
\hline Anti-ds DNA & Positive & 14 & 1 & 15 & $0.0000^{* *}$ \\
\hline & Negative & 1 & 9 & 10 & \\
\hline ANA & Positive & 15 & 10 & 25 & \\
\hline & Negative & 0 & 0 & 0 & \\
\hline
\end{tabular}

$* *$ = highly significant at $\mathrm{P}$ value $<0.01$

Table 3: Relationship between MMP-9 level and patients with renal affection in SLE

\begin{tabular}{|l|l|l|l|l|l|}
\hline & & MMP-9 & & & \\
\hline & & Positive & Negative & Total & P value \\
\hline Renal & Positive & 13 & 3 & 16 & $0.0038^{* *}$ \\
\hline & Negative & 2 & 7 & 9 & \\
\hline
\end{tabular}

$* *$ = highly significant at $\mathrm{P}$ value $<0.01$

Table 4. : Relationship between MMP-9 level and raynaud's phenomenon in SLE patients

\begin{tabular}{|l|l|l|l|l|l|}
\hline & & MMP-9 & & & \\
\hline & & Positive & Negative & Total & P value \\
\hline Raynaud's & Positive & 13 & 1 & 14 & $0.0002^{* *}$ \\
\hline Phenomenon & Negative & 2 & 9 & 11 & \\
\hline
\end{tabular}

$* *$ = highly significant at $\mathrm{P}$ value $<0.01$ 
Table 5: Relationship between MMP-9 level and presence of malar rash and photo sensitivity in SLE patients.

\begin{tabular}{|l|l|l|l|l|l|}
\hline & & MMP-9 & & & \\
\hline & & Positive & Negative & Total & P value \\
\hline Malar & Positive & 13 & 1 & 14 & $0.0002^{* *}$ \\
\hline & Negative & 2 & 9 & 11 & \\
\hline Photo & Positive & 13 & 1 & 14 & $0.0002^{* *}$ \\
\hline & Negative & 2 & 9 & 11 & \\
\hline
\end{tabular}

Table 6: Relationship between MMP-9 level and presence of alopecia and mucosal ulcers in SLE patients.

\begin{tabular}{|l|l|l|l|l|l|}
\hline & & MMP-9 & & & \\
\hline & & Positive & Negative & Total & P value \\
\hline Alopecia & Positive & 8 & 2 & 10 & 0.0956 (NS) \\
\hline & Negative & 7 & 8 & 15 & \\
\hline $\begin{array}{l}\text { Mucosal } \\
\text { ulcers }\end{array}$ & Positive & 5 & 2 & 7 & 0.4670 (NS) \\
\hline & Negative & 10 & 8 & 18 & \\
\hline
\end{tabular}

$\mathrm{NS}=$ non significant

Fig MMP-9 among patients and control groups

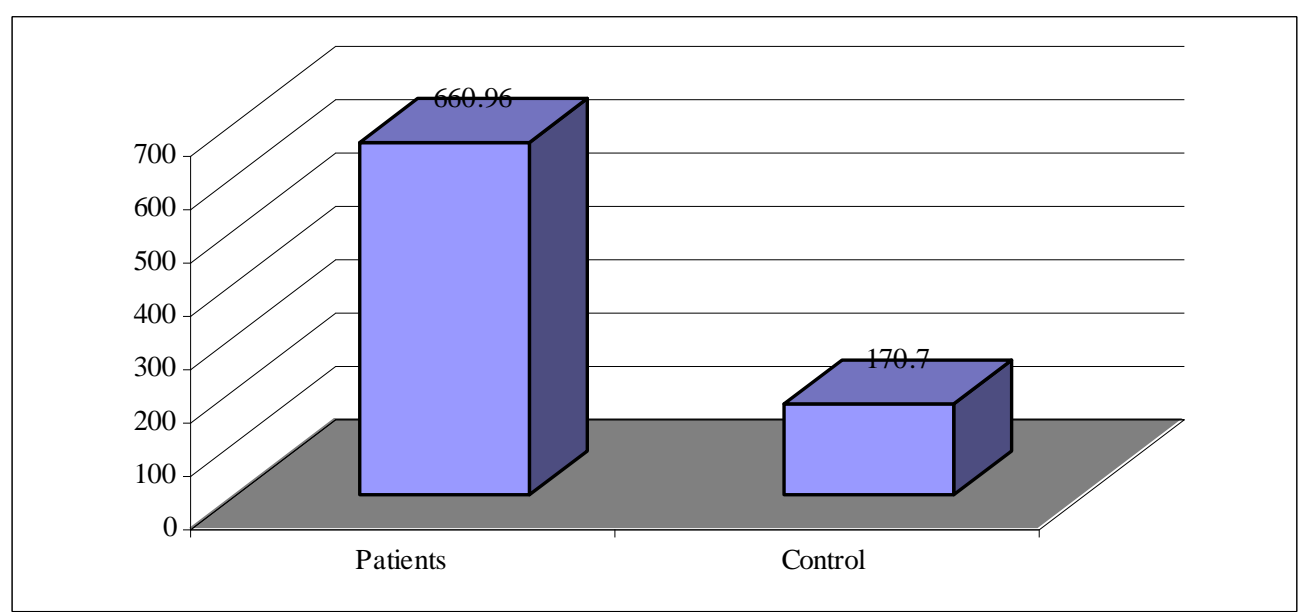

\section{Discussion}

Systemic lupus erythematosus (SLE) is an autoimmune disease characterized by the increased production of autoantibodies and by T-cell dysfunction associated with general clinical manifestations (Faber Elmann et al. 2002 A).

Matrix metalloproteinase-9 (MMP-9) was involved in inflammation and immune system dysfunctions. Beside immunologic abnormalities, SLE also presents chronic inflammatory components. Therefore, a role of MMP-9 in SLE pathology was supposed (Matache et al., 2003).

In the present study, serum level of MMP-9 was investigated to determine its value in monitoring SLE disease activity. We investigated the level of MMP-9 in the sera of 25 SLE patients compared with 10 healthy controls. The serum level of MMP9 was significantly higher in all studied SLE cases when compared with the control level $(\mathrm{P}<0.01)$. These results are in 
agreement with that of Liu et al, 2004 and Matache et al 2003 who reported that MMP-9 level in sera of SLE patients is significantly higher than those in normal control

There was significant correlation of serum MMP-9 with anti-ds DNA antibodies. These results were not in agreement with Makowski and Ramsby 2003 who found that serum MMP-9, inversely correlates with anti-ds DNA antibodies, which are a specific marker for SLE, so it may be important in monitoring disease activity during antibody deposition in tissues. There was no significant correlation of serum MMP-9 with anti-nulcear antibodies.

There was significant correlation between serum MMP-9 and the presence of lupus nephritis. These results were not in agreement with Faber-Elmann et al. (2002 B) and Liu et al. (2004) who found no correlation between serum MMP-9 and renal involvement. Mc Millan et al. 1996 demonstrated that MMP-9 is produced by glomerular epithelial cells.

There was significant correlation between serum MMP-9 and the presence of raynaud phenomenon. These result were in agreement with Faber-Elmann et al (2002) $\mathrm{B}$ who found a correlation between high serum MMP-9 and raynaud phenomenon.

There was significant correlation of serum MMP-9 with malar rash and photosensitivity. These results were in agreement with Faber-Elmann etal. (2002) $\mathrm{B}$ who found strong correlation between high serum MMP-9 and presence of malar rash and photosensitivity.

There was no significant correlation of serum MMP-9 with presence of alopecia and mucosal ulcers. These results were not in agreement with Faber-Elmann et al. (2002) B who found strong correlation between serum MMP-9 and presence of mucosal ulcers .

The origin of the elevated MMP-9 in sera of SLE patients is not known. MMP-9 has been shown to be secreted by peripheral blood cells such as T-cells, neutrophils and macrophages (Matache et al. 2003).

It has also been demonstrated that MMP-9 is produced by glomerular epith- elial (McMillan et al, 1996) and mesangial cells (Lovett et al, 1992) as well as by pleuntic cells. Moreover, the association between cytot-oxic treatment, which represents the severity of SLE- related organ impairment, and high serum MMP-9 in the sera support the notion that the diseased organs are the source of MMP-9 activity in SLE patients (Faber-Elmann et al. 2002B).

TNF - $\alpha$ and IL-1 were shown to play an important role in the pathogenesis of SLE (Segal et al. 1997). It has been shown in several systems that these cytokines induce MMP-9 production (Guedez et al, 1996) and thus the inducation of the latter MMPs in part of the pathogenic effect of these cytokines in SLE. MMPs of both T cells and macrophages facilitate secretion of TNF $\alpha$ by cleavage of membrane-bound form (Gearing et al. 1994).

Thus, these examples demonstrate the mutual regulatory effects of MMP on the pro-inflammatory cytokines and vice versa.

We conclude that MMP-9 might play a role in the pathogenesis of SLE, and the measurement of plasma/serum activity levels of this metalloproteinase may provide important information when monitoring patients treated with drug that interfere with MMP-9 activity.

\section{References}

1. Brehmer B. Biester Feld S. and Jakse G.: Expression of matrix metalloproteinases (MMP-2 and -9) and their inhibitors (TIMP-1 and -2) in prostate cancer tissue. Prostate cancer and prostatic Disceases 6, 217-222. (2003).

2. Faber-EImann A., Eilat E., Zinger H., and Mozes e.: A peptide based on an antiDNA autoantibody downregulates matrix metalloproteinases in murine models of lupus. Clin Immunol. Nov.; 105 (2): 223232 (2002) A.

3. Faber-Elmann A., Sthoeger Z., Tcherniack A; et al: Activity of matrix metallopr-oteinase -9 is elevated in sera of patients with systemic lupus erythematasus. Clin. Exp. Immunol. 127:393-398 (2002) B.

4. Gearing AJA, Beckett P., Christodoulou M.; et al. Processing of tumour necrosis 
factor alpha precursor by metalloproteinases. Nautre; 370:555-557. (1994).

5. Guedez L., Lim Ms., and Stetler stevension WG. The role of metalloproteinases and their inhibitors in hematological disorders. Crit, Rev. oncogenesis ; 7: 205-225 (1996).

6. Hahn BH. An overview of the pathogenesis of systemic lupus erythematosus In: Wallace DJ, Hahn BH. Eds. Dubois, lupus erythematosus philadelphia: will, ams and wilkins: 69-76 (1993).

7. Liu Y, Zheng M., Yin WH, and 2 hang B., Relationship of serum levels of HGF and MMP-9 with disease activity of patients with systemic lupus erythematasus. Zhejiang da xue xue bao yi xue ban , Jul; 33 (4): 340-3, 398 (2004).

8. Lovett DH. Johnson RJ, Marti HP and et al. Structural characterization of the mesangial cell type IV collagenase and enhanced expression in a model of immune complex mediated glomerulonephritis. Am, J. pathol , 141:85-98 (1992).

9. Makowski GS, and Ramsby ML. Concentrations of circulating matrix metalloproteinase 9 invesrsely correlate with autoimmune antibodies to double stranded DNA: implications for monitoring disease activity in systemic lupus erythematosus. Mol. Pathol. Aug, 56(4): 244-247 (2003).

10. Matache C. Stefanescu M., Dragomir C., and et al. Matrix metallo proteinase -9 and its natural inhibitor TIMP-1 expressed or secreted by peripheral blood mononuclear cells from patients with systemic lupus erythematosus. J. Autoimmun. June; 20 (4): 323-331 (2003).

11. Mc Millan JI, Riordon JW, couser WG and et al., characterization of a glomerular epithelial cell metalloproteinase as matrix metalloproteinase-9 with enhanced expression in a model of membranous nephropathy. J. Clin. Invest. 97:1094-1101 (1996).

12. Segal R. Bermas BL. Dayan M. and et al., Kinetics of cytokine production in experimental systemic lupus erythematosus: involvement of $\mathrm{T}$ helper cell $1 / \mathrm{T}$ helper cell 2type cytokines in disease. J. Immmunol ; 158: 3009-3106 (1997).

13. Wallace G.R, Whiston AR., Stanford MR. And et al., The matrix metalloproteinase inhibitor BB-1101 prevents experimental autoimmune unveoretinitis (EAU). Clin Exp. Immunol , 1108:364-370. (1999).

14. Winchester RJ. Systemic lupus erythematosus pathogenesis. In. Koopman WJ. Eds Arthritis and Allied Conditions Birmingham Alabama: William and wilkins : 1361-1391 (1996).

15. Zhang Y. , Mc Cluskey K. Fujii K and et al., Differential regulation of monocyte matrix metalloproteinase and TimP-1 production by TNF - $\alpha$, granulocyte-macrophage CSF, and IL-1B through prostaglandindependent and independent mechanisms. J. Immunol , 161: 3971-3076 (1998). 
قياس مستوي الأنزيم البروتيني الفلزي-9 في مصل الدم في مرضى الأئة الحمراء الفلز في

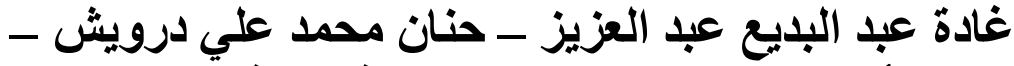

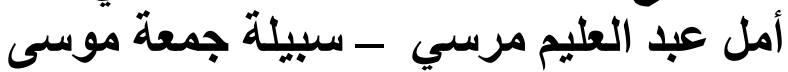

من أقسام الأمراض الجلاية والباثولوجياً الإكلينيكية والباطنة العامة بكلة بكلية طب بنات جامعة الأزهر الألوله

يشارك الانزيم البروتيني الفلزي -9 في حدوث الالتهابات واضطر اب الجهاز المناعي

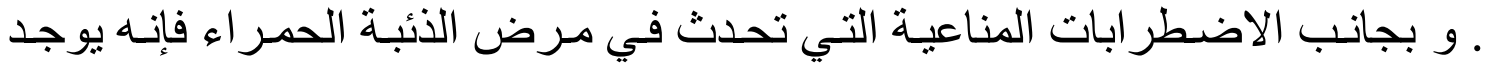

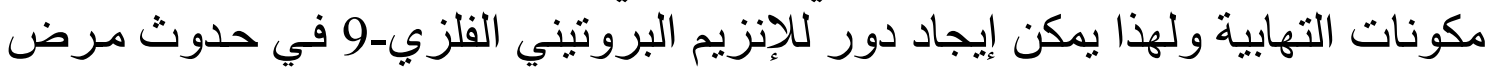

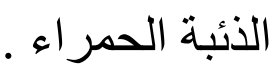

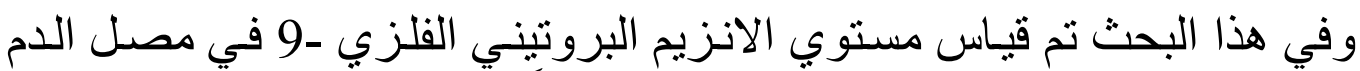

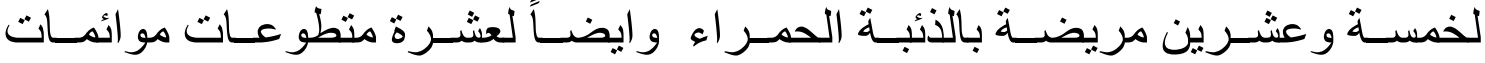

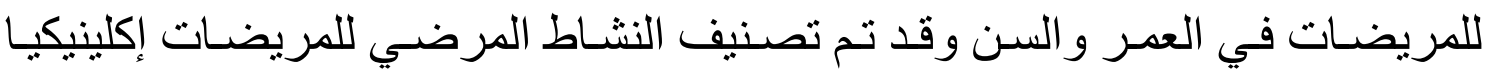

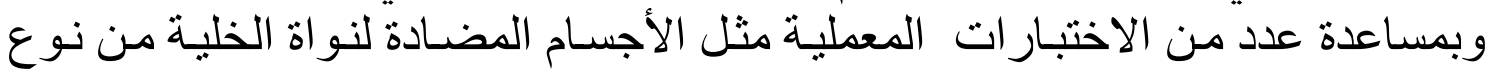
. (anti ds DNA)

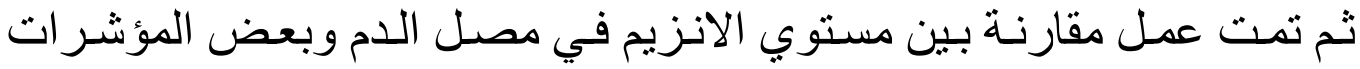

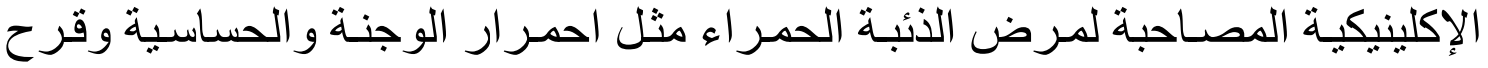

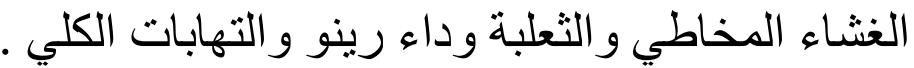

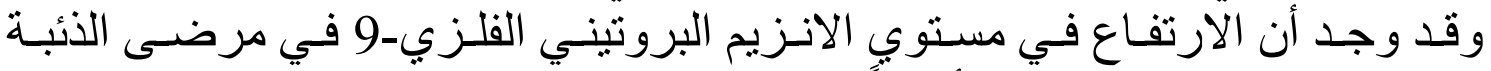

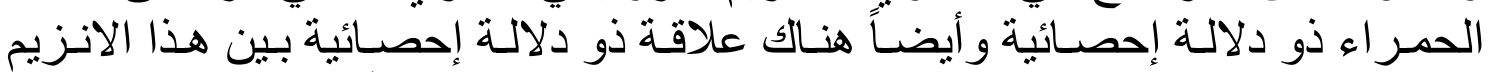

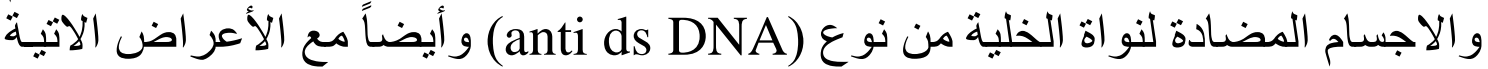

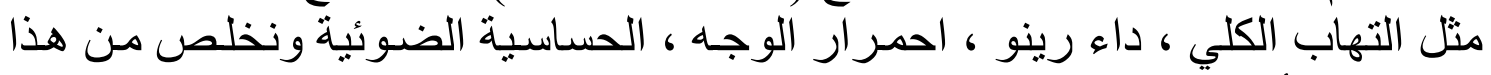

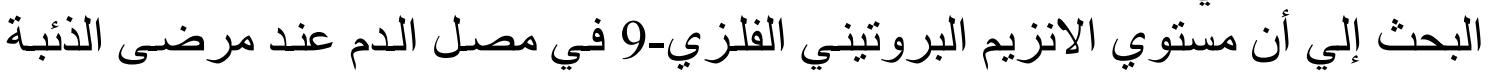

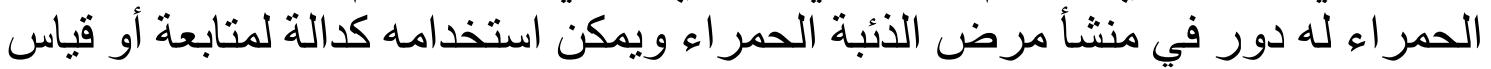
درجة النشاط المرضي لهذا المرض. 